\title{
Neurological sciences impact factor 2017 is increased to 2.285: a comment from the Editor in Chief
}

\section{Antonio Federico ${ }^{1}$}

Published online: 3 July 2018

(C) Springer-Verlag Italia S.r.l., part of Springer Nature 2018

In this month, usually the Scientific Journals Editors have some input on their activity after the publication by Thomson Reuters-ISI of the Journal Impact Factor (IF) value, derived by the article citations in the International Journals on the previous 2 years.

With satisfaction, we recorded that our 2017 IF is 2.285 with a significant increase if related to the past years.

This data convinced me to do some considerations on our work.

Figure 1 reports our IF in the past 5 years, showing a progressive trend to increase with a significant change on the 2017, when IF reached the value of 2.285 .

Figure 2 shows the numbers of accepted in relationship to the submitted articles. Rejection rate for the 2017 was $69.9 \%$.

The IF growth is mainly due to the increase in the number of citations despite a slight decrease in source items has been recorded as well, as reported in Fig. 3.

The IF increase was related to the good article selection, $63 \%$ of them receiving citations.

I wish to express my gratitude to all the Editorial staff, the Editorial Board, the Associate Editors, and the Reviewers for their good work in the evaluation and selection of the papers.

I also would like to thank all contributors for choosing our journal, that now may be more attractive in relationship to the increased IF.

I hope, finally, that our efforts will continue in the future, improving years after years our quality and our qualified presence in the editorial world panorama.

The IF increase reaching a value higher than 2 is also an important success for the Italian Neurology (the Italian

Antonio Federico

federico@unisi.it

1 Department of Medicine, Surgery and Neurosciences, Medical School, University of Siena, Siena, Italy

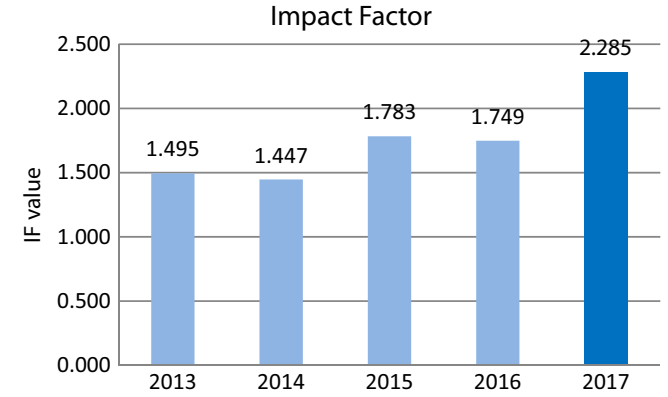

Fig. 1 Changes of neurological sciences IF over the last years

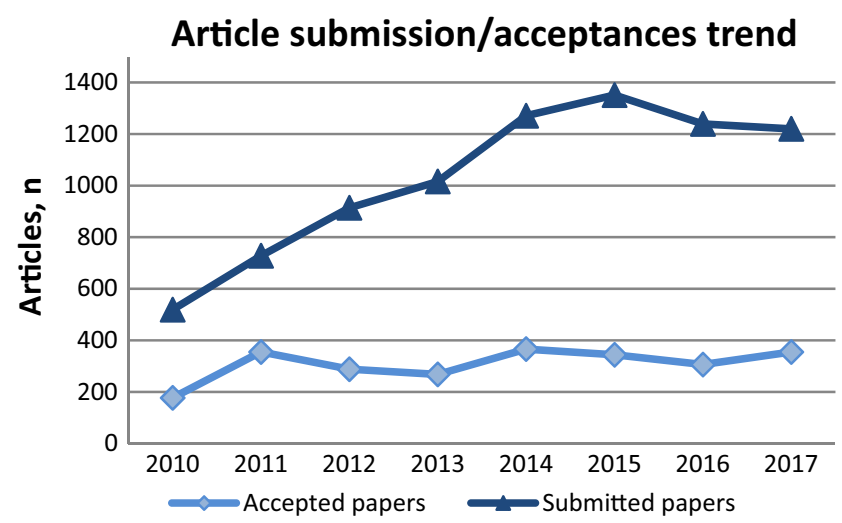

Fig. 2 Article submissions and acceptances from 2010 to 2017

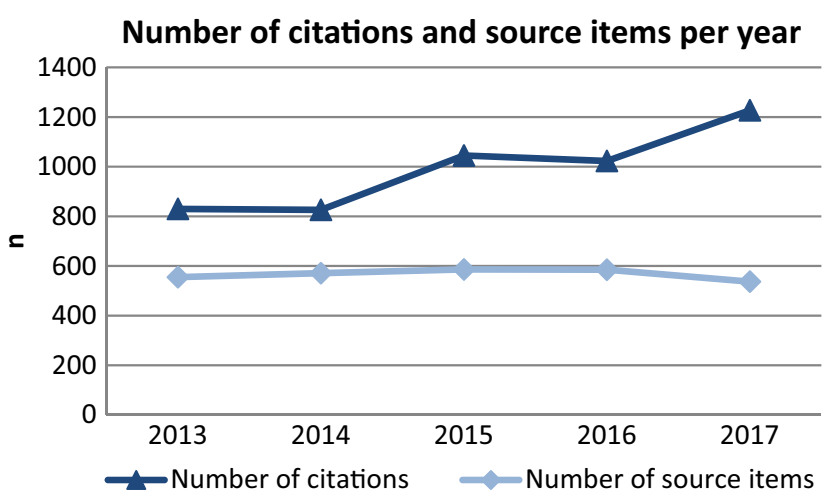

Fig. 3 Number citations and sources per year from 2013 to 2017 
Neurological Society is the owner of the Journal)), that is one of the most active world community for their scientific production [1].

Prof. Antonio Federico

Editor in Chief

\section{References}

1. Cruccu G, Deuschl G, Federico A (2018) Scientific publications of European neurologists: a survey commissioned by the European Academy of Neurology. Eur J Neurol. https://doi.org/10.1111/ene. 13666 